\title{
O uso de aplicativos para o desenvolvimento das crianças na educação infantil: utilização de aplicativos virtuais na prática docente
}

Este estudo traz à luz a importância dos multimeios digitais para o desenvolvimento das crianças na educação infantil, tendo como intuito evidenciar as novas plataformas e modalidades de ensino, bem como expor as vantagens, contribuições e barreiras para sua inserção. Busca-se, também, discutir como as novas ferramentas digitais pedagógicas podem ser benéficas, no auxílio ao trabalho docente. O objetivo do trabalho é expor a relevância da interatividade, dos aparatos tecnológicos e aplicativos no ambiente de ensino, em especial, para a educação infantil, por meio da implementação de um aplicativo voltado para a facilitação da aprendizagem do discente em sala de aula. A metodologia deste trabalho é embasada em conceitos que atendem à pesquisa com seu tema principal; desse modo, o atual estudo terá abordagem qualitativa e exploratória. Conclui-se que este tipo de aplicação móvel, destinado a auxiliar a aprendizagem das crianças, revela-se útil, uma vez que se identifica facilidades de uso, sua interatividade e sua intenção, de modo amplo, em utilizar as atividades de suporte projetadas para o aprendizado.

Palavras-chave: Educação Infantil; Mutimeios; Aplicativo; Aprendizagem.

\section{The use of applications for children's development in early childhood education: the use of virtual applications in teaching practice}

This study highlights the importance of digital multimedia for the development of children in early childhood education, aiming to highlight the new platforms and teaching modalities, as well as exposing the advantages, contributions and barriers to their insertion. It also seeks to discuss how the new digital pedagogical tools can be beneficial in helping the teaching work. The objective of this paper is to expose the relevance of interactivity, technological devices and applications in the teaching environment, especially for early childhood education, through the implementation of an application aimed at facilitating student learning in the classroom. The methodology of this work is based on concepts that meet the research with its main theme; Thus, the current study will have a qualitative and exploratory approach. It is concluded that this type of mobile application, intended to help the learning of children, proves to be useful, since it identifies ease of use, its interactivity and its intention, in a broad way, to use the support activities designed to the learning.

Keywords: Child education; Mutimes; App; Learning.

Topic: Tecnologia, Educomunicação e Cibercultura

Reviewed anonymously in the process of blind peer.
Received: 07/01/2019

Approved: 08/02/2019
Rossana Platchek Wolinger (iD)

Centro de Educação Infantil Santa Rita de Cássia, Paraguai http://lattes.cnpq.br/1883735890860923

http://orcid.org/0000-0001-7840-2008

rossapla@bol.com.br
Referencing this:

WOLINGER, R. P.. O uso de aplicativos para o desenvolvimento das crianças na educação infantil: utilização de aplicativos virtuais na prática docente. Educationis, v.7, n.1, p.11-20, 2019. DOI: http://doi.org/10.6008/CBPC2318-3047.2019.001.0002 


\section{INTRODUÇÃO}

Com o surgimento e a atualização contínua das Tecnologias de Informação e Comunicação (TICS), o contato com diferentes estratégias de ensino foi se tornando cada vez mais frequente nas Instituições de Educação Infantil. O uso da internet tem contribuído significativamente no ensino e aprendizagem das crianças, tornando-se uma grande aliada daqueles que estão nos estágios de aprender e desenvolver suas proficiências em face ao desenvolvimento infantil, seja intelectual, psicológico, sensório-motor e assim por diante.

Atualmente, a busca pelo aprendizado e formas de ensino através das novas tecnologias tem aumentado gradativamente, contribuindo para o crescimento e fortalecimento da Educação Infantil. Cada vez mais, as pessoas têm dedicado seu tempo ao uso da internet, construindo autonomia para aprender sobre diferentes aspectos através do acesso a aplicativos e jogos que permitem aprender e progredir no aperfeiçoamento de habilidades.

A riqueza de informação em grande quantidade no ciberespaço de todas as ferramentas e recursos disponíveis a um click têm auxiliado milhares de educandos a desenvolverem a autonomia de ensino/aprendizagem no meio virtual, "possibilitando aprendizagem mais significativa e colaborativa, já que o estudante ao construir seu próprio conhecimento, passa a ter papel ativo na busca de solução de suas necessidades e da coletividade" (SERAFIM et al., 2008).

Os jogos eletrônicos têm ocupado um grande espaço na vida de crianças, adolescentes e adultos, influenciando a maioria a aprender e aperfeiçoar os níveis de inglês ou funcionando como uma ferramenta eficiente e de forma prazerosa no entretenimento do jogo, como Prensky (2007) sugere em sua obra: "o prazer e a diversão como parte do processo de aprendizagem são importantes ao aprender novas ferramentas, uma vez que o aprendiz está relaxado e motivado e, portanto, mais disposto a aprender" (PRENSKY, 2007).

Com esse trabalho, objetiva-se mostrar ao leitor que é possível aprender e/ou se desenvolver amplamente na Educação Infantil através das práticas presentes nas Tecnologias Digitais, reconhecendo os jogos eletrônicos como importantes ferramentas para o desenvolvimento de ensino e aprendizagem. Dessa forma, cabe dizer que tal desenvolvimento contribui para o aprimoramento de práticas sociais adolescidas por meio da linguagem nos processos de leitura, escrita, escuta e fala de textos de vários.

Desse modo, esta pesquisa tem por objetivo principal analisar o uso de tecnologias, sejam aplicativos, jogos digitais, entre outros, no ensino das crianças na Educação Infantil, frente à perspectiva da multimodalidade e do letramento digital. Para tanto, será necessário identificar qual a relevância da prática pedagógica frente ao uso dos jogos digitais utilizados por professores; verificar se o uso dos jogos muda a prática dos docentes ou não interferem na forma na qual desenvolvem sua metodologia de trabalho; e demonstrar o impacto do uso das tecnologias digitais na aprendizagem dos educandos.

O uso de tecnologia como forma de desenvolvimento infantil perpassa pela ideia central de que a educação necessita de estar em harmonia com os progressos tecnológicos, uma vez que os aparatos 
eletrônicos facilitam o processo de aprendizagem (RIBEIRO, 2006). Portanto, o objetivo central deste estudo é evidenciar a importância da implementação de um aplicativo para o desenvolvimento das crianças na educação infantil.

Logo, o presente estudo levanta a proposição da utilização das novas tecnologias e multimeios aplicativos pedagógicos, jogos estratégicos, mídias digitais - para alunos da Educação Infantil; novidades que podem sugerir atividades diferenciadas que possam integrar os planos de aula para todos os professores, de modo geral e, por conseguinte, gerar uma adaptação de conteúdo para os educandos de cada etapa da Educação Infantil. A problemática ocorre frente à pergunta: é possível otimizar o processo de ensinoaprendizagem das crianças por meio do uso das inovações tecnológicas?

\section{METODOLOGIA}

O presente estudo se caracterizará como qualitativo e descritivo. Em relação à abordagem, foi realizado através de uma pesquisa qualitativa, com o intuito de descrever uma situação específica, utilizando o processo e seu significado como focos principais da abordagem. Evidencia-se que as pesquisas qualitativas podem ser classificadas sob o enfoque subjetivista e compreensivista, ou sob um enfoque mais crítico, com visão histórico-estrutural.

Assim, através das percepções, reflexões, e até da intuição, a realidade é conhecida para que se possa mudá-la e transformá-la. Segundo Gil (2017), as pesquisas descritivas, salientam-se aquelas que têm por objetivo estudar as características de um grupo. Portanto, o presente trabalho pode ser classificado como descritivo.

Conforme Gil (2017), a pesquisa é feita mediante conhecimentos acessíveis com a execução de métodos e técnicas de investigação, abarcando diversas etapas. De acordo com o mesmo autor, uma pesquisa, pode ser compreendida como um processo formal e sistemático de desenvolvimento do modo científico na qual são descobertas respostas ou são comprovadas hipóteses para as quais foram formulados questionamentos e apresentados problemas. A metodologia deste trabalho é embasada em conceitos que atendem a pesquisa com seu tema principal, desse modo, o atual estudo tem abordagem qualitativa e exploratória (GIL, 2017).

Portanto, este trabalho desenvolve-se por meio de pesquisas bibliográficas para a fundamentação teórica e, assim, buscou-se relacionar autores que permeiam seus estudos nessa esfera, bem como trazer à luz a relevância da utilização de tecnologias no ambiente escolar, em especial, na utilização de aplicativos para a Educação Infantil.

\section{DISCUSSÃO TEÓRICA}

\section{A Importância da Utilização de Aplicativos Virtuais na Prática Docente}

De acordo com Antunes (2008), a disponibilidade de materiais e conteúdos gera, no aluno, a capacidade de desenvolvimento de habilidades de independência e iniciativa, uma vez que há uma 
valorização da experiência individual. Desta forma, é importante entender que os aparatos tecnológicos, em especial a utilização de aplicativos auxiliam e possibilitam, à educação, um viés integrado, colaborativo e contínuo.

As novas modalidades de ensino e suas tecnologias estão cada vez mais operantes nos mais diversos países ao redor do mundo, o uso de tais aparelhos ainda está por consolidar dentro dos estratos acadêmicos e ainda está para se tornar comum em toda a extensão do nosso país. Em 2002, Marc Rosenberg sugeriu a definição de e-Learning como sendo a utilização de tecnologias de internet para fornecer uma ampla gama de soluções que melhoram o conhecimento e o desempenho. Entretanto, o e-learning é mais do que o uso de tecnologias de internet (CONFORTO et al., 2015).

Em 2003, outra definição foi proposta por Derek Stockley, na qual a conceituação de e-learning é o envolvimento da utilização de um computador ou dispositivo eletrônico para fornecer material de treinamento, educacional ou de aprendizagem. Assim, pode-se entender que as tecnologias em uso no ambiente de ensino permitem que aos grupos de interesse uma comunicação forte, uma vez que o acompanhamento e até mesmo a orientação que é gerada neste meio fazem com que o alunado adquira mais confiança em si mesmos (SILVA, 2015).

Para o professor, seja da Educação Infantil ou das demais etapas das Educação Básica, lidar com a tecnologia tem se tornado um desafio cada vez maior, uma vez que com a inserção e o avanço dos recursos tecnológicos em sala de aula há a necessidade de adaptação, tanto em nível de conhecimentos técnicos quanto tecnológicos. É importante, também, compreender que o dinamismo tecnológico tem incorporado cada vez mais o ambiente escolar, desta forma, vê-se que tablets estão praticamente substituindo os livros e, atualmente, pode-se pesquisar tudo que se deseja no próprio dispositivo móvel (CONFORTO et al., 2015).

As mídias sociais se tornaram comuns e a maneira como as crianças usam a tecnologia transformou completamente a maneira como vivem. Dito isto, na sala de aula, a tecnologia causa muitos impactos, sendo, de modo geral, positivo, haja vista que, no processo educacional, os próprios educadores também reconhecem a importância de desenvolver essas habilidades tecnológicas nos alunos para que eles estejam preparados para seu amplo desenvolvimento escolar (SILVA, 2015).

O impacto que a tecnologia tem nas escolas e nos Centro de Educação Infantil de hoje é bastante significativo. Esta adoção generalizada da tecnologia mudou completamente como os professores ensinam e os alunos aprendem. Conclui-se que ao abraçar e integrar a tecnologia na sala de aula, tem-se gerado uma preparação nos alunos para uma vida bem-sucedida fora da escola (BERSCH et al., 2014).

\section{Implementação de Aplicativos para Educação Infantil: Oportunidades}

A implementação de aplicativos pedagógicos para Educação Infantil pode gerar muitos benefícios para o ambiente escolar. Nesse sentido, é importante compreender que a inserção de um aplicativo para Educação Infantil pode ajudar na socialização dos educandos, bem como pode atenuar a relação de dependência das crianças em relação ao convívio social no ambiente escolar e fora dele. 
Destarte, a implementação do uso de aplicativos educacionais para Educação Infantil é positiva no ambiente escolar e se torna uma ferramenta de suporte para o grupo de interesse. Nota-se que os aparatos tecnológicos estão ficando cada vez mais acessíveis ao longo do processo histórico, deste modo, há, atualmente aplicativos cada vez mais específicos e portáteis, facilitando o seu uso nas mais diversas situações de aprendizado (FERNANDES, 2007).

Hoje os jovens educandos se caracterizam por pertencer à geração dos nativos digitais, aquela parcela da população que nasceu após a invenção da internet. É por isso que a incorporação de tecnologia na educação oferece uma série de benefícios que ajudam a melhorar a eficiência e a produtividade na sala de aula, além de aumentar o interesse de crianças e adolescentes em atividades acadêmicas (SILVA, 2015).

A Internet e o acesso a dispositivos móveis cada vez mais intuitivos colocaram uma mudança de paradigma no uso da tecnologia. Essa mudança também é evidente no campo da educação, no qual mais e mais coisas podem ser feitas, aproveitando a rede e suas possibilidades, tanto na sala de aula quanto fora dela. Mas não devemos pensar que esses processos são novos. Na verdade, a tecnologia tem ajudado professores e alunos em seu trabalho diário por vários anos. Processadores de texto, calculadoras, impressoras e computadores são usados há décadas para diferentes atividades estudantis (AYRES, 2012).

No entanto, agora com a Internet e a tecnologia móvel em expansão, ainda mais elementos tecnológicos são incorporados ao ambiente educacional. Quadros interativos, salas de aula virtuais e uma série de recursos eletrônicos para realizar pesquisas ou realizar trabalhos escolares são algumas das maneiras pelas quais a tecnologia digital foi integrada a escolas e universidades.

É um momento de grandes oportunidades. Universidades têm usado tecnologias para expandir o acesso à educação. Desse modo, essa realidade deve alcançar o pátio da escola, por meio de instituições inovadoras que se empenham, mesmo com todas as dificuldades, em implementar experiências de aprendizado altamente inovadoras (SILVA, 2015).

A partir das exposições neste trabalho, tem-se que a tecnologia sempre esteve presente na educação. As novas tecnologias, inclusive com ferramentas de informática tem se apresentado como recursos diferenciados no processo de ensino-aprendizagem, que favorecem o aprendizado por ser algo que estimula o interesse dos alunos. Entretanto, em se tratando destas novas tecnologias, não basta apenas conhecê-las, tendo em vista a necessidade de conhecimento sobre como utilizá-las, de forma que consiga explorar ao máximo os conteúdos escolares e sua aplicação na realidade dos alunos (PIROZI, 2013).

Por isso, se faz importante humanizar as tecnologias, inserindo as mesmas no meio educacional ao mesmo tempo em que se prepara os professores para utilizá-las. A tecnologia não tem a capacidade de salvar a educação, mas é altamente capaz de promover o conhecimento quando utilizada a contento (MORAN, 2000). Desta forma, os professores devem buscar dados, apresentá-los, promover o conhecimento a partir de informações, ao mesmo tempo em que se estimula a inteligência e a capacidade de raciocínio dos alunos. Nesse contexto, o ser humano se apresenta como peça fundamental para que as tecnologias tenham sentido no contexto escolar. Não basta ter a tecnologia à disposição quando não se tem seres humanos preparados para lidar com elas. 


\section{A Pedagogia dos Multiletramentos}

Pirozi (2013) narra que, em setembro de 1994, um grupo formado por dez teóricos de diferentes áreas, do qual eles eram parte, se reuniram na cidade de Nova Londres nos Estados Unidos para discutir sobre os novos caminhos da educação. Considerando as diferenças culturais, e tendo como base suas diferentes áreas de atuação e especialização, eles estabeleceram como foco repensar a premissa fundamental da pedagogia do letramento e retornar à questão da necessidade dos aprendizes e o que eles precisam aprender considerando as mudanças no mundo e suas novas demandas.

O resultado das discussões foi o que gerou o termo 'multiletramentos' e para isso dois argumentos foram utilizados. O primeiro relaciona-se com a multiplicidade dos canais de comunicação e da mídia e o segundo com o aumento da diversidade cultural e linguística. O diagrama abaixo ilustra como a pedagogia dos multiletramentos engloba os 'multis'.

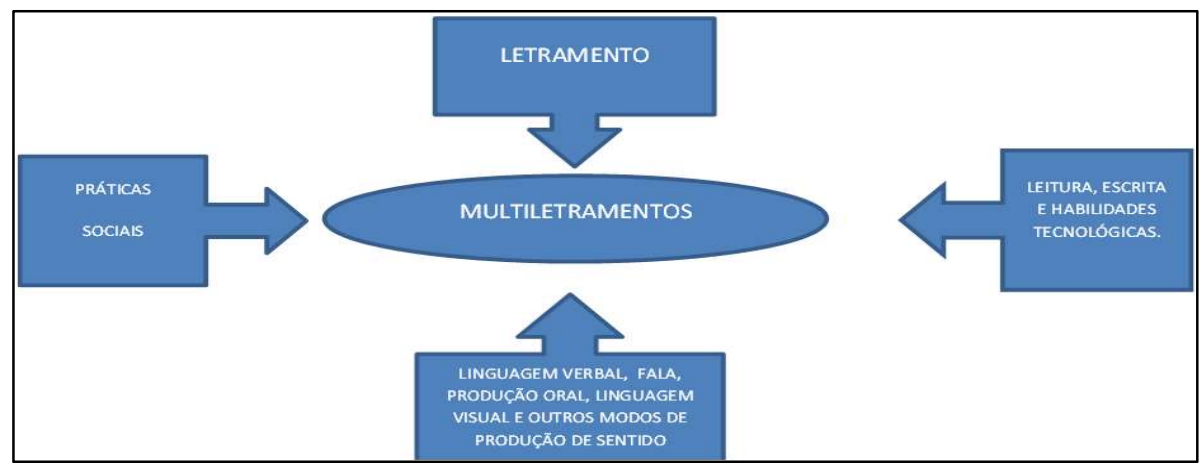

Figura 1: Práticas de Ensino de Língua Inglesa e as Tecnologias. Fonte: Pirozi (2013).

Os teóricos ali presentes compartilhavam a visão de que em cada um dos países de onde vinham, o que os alunos precisavam aprender estava mudando. Seguindo essa premissa, a pedagogia dos multiletramentos tem foco nos modos de representação mais amplos de linguagem. Os significados são feitos formas cada vez mais multimodais. São exemplos disso, a internet, a mídia interativa, a facilidade de fazer vídeos, de publicar textos, etc.. O termo letramento permanece centrado na linguagem apenas (PIROZI, 2013). Para Ayres (2012), as novas mídias de comunicação estão reestruturando a maneira como utilizamos a linguagem. Para os autores, essas questões são fundamentais para o futuro do ensino e aprendizagem no qual educadores e alunos precisam ser participantes ativos nas mudanças sociais, tornando-se aprendizes e estudantes que podem ser ativos designers (criadores) de futuros sociais.

Nas discussões, foram estabelecidos seis elementos teóricos para o processo de produção de sentido, são eles: significado linguístico, significado visual, significado auditivo, significado gestual, significado espacial, e os padrões multimodais de sentido que relacionam os primeiros padrões de significados entre si. Segundo Ayres (2012), apenas esses padrões são capazes de informar "como" e "o quê".

Além dos elementos teóricos, também foram considerados quatro componentes da pedagogia, segundo Pirozi (2012): a experimento/prática, que está ligada ao aprendizado no contexto escolar mas também envolve a realidade do aluno em seu cotidiano; a conceitualização, instrução explícita, que seria a construção do conhecimento por parte do aluno; o desenvolvimento da capacidade crítica, que envolve 
análise mais profunda dos textos; e a aplicação prática, que é o conhecimento em ação gerando transformação. Seguindo esses novos parâmetros, a relação entre professores e alunos passa a ser mais colaborativa para a construção do conhecimento dos alunos, pois como mencionando anteriormente, a educação atual enfrenta um desafio de se adequar às novas formas de aprendizagem dos alunos.

\section{Multimodalidade}

Moran (2000) coloca em evidência a relação entre letramento e aspectos sociais, tecnológicos e econômicos. Ilustrando as mudanças que ocorreram nessas áreas, Kress (2000) cita duas grandes mudanças que influenciaram fortemente o Letramento. A primeira mudança é a dominância da escrita que cedeu lugar à dominância da imagem, e a segunda é a dominância dos livros que cedeu lugar à dominância das telas. Para Moran (2000), as mudanças mencionadas levantam duas questões importantes a serem refletidas: qual é o provável futuro do letramento e quais são os prováveis efeitos sociais e culturais de nível maior dessas mudanças?.

Segundo Kress (2000), a linguagem falada permanecerá como principal modo de comunicação, a linguagem escrita será em muitos domínios de comunicação substituída pela imagem e, apesar disso a linguagem escrita permanecerá como modo favorito de comunicação em contextos políticos e em elites sociais. Os efeitos na escrita, sob a dominância da imagem e da utilização de telas, irão produzir profundas mudanças nas formas e nas funções da linguagem (MORAN, 2000).

Kress (2003) diferencia a organização lógica entre escrita e imagem enfatizando que a escrita é diacrônica e segue a ordem de seus elementos, já a imagem é regida pela lógica do espaço e pela lógica da simultaneidade dos seus elementos na organização espacial. $O$ autor estabelece o conceito de Affordances que, no evento de comunicação, relaciona-se à cada modo de comunicação que se pode oferecer a fim de estabelecer sentido.

Nesse viés, o locutor deve selecionar seus modos de acordos com seus affordances para facilitar a construção de sentido para o interlocutor. Segundo Kress (2003), a escrita e letramento não são obrigatoriamente a mesma coisa, ele estabelece que escrever é fazer marcas em uma superfície com o intuito de gravar algo. Essas marcas podem ser letras, imagens, desenhos, etc.. Kress (2003) ainda exemplifica falando de sistemas que utilizam letras e outros sistemas que não utilizam, como os símbolos do sistema de escrita chinês, japonês, de civilizações antigas entre outros.

Ademais, pode-se inferir que estamos acostumados à escrita alfabética por convenção visual. Nos tempos medievais e até mesmo na Europa moderna, a escrita não separava palavras umas das outras de maneira tão marcada; naquele contexto, aprender as palavras da escrita partiu de saber as palavras faladas. O início do desenvolvimento da escrita das crianças exemplifica isso bem, pois geralmente são sequência de letras com espaços entre elas, mesmo sem fazer sentido. Isso mostra que as crianças reconhecem as palavras como unidades visuais e como se cada uma unidade tivesse um significado. 


\section{Os jogos digitais no ensino}

Com a popularização dos jogos eletrônicos, o número de usuários deste tipo de entretenimento foi se tornando cada vez maior. Este tipo de jogo pode desenvolver várias habilidades: concentração, memória, raciocínio, agilidade, atenção, paciência, etc.. O desenvolvimento dessas habilidades colabora grandemente na aprendizagem e no desenvolvimento global dos educandos da Educação Infantil, já que para se aprender dentro da alfabetização e da lógica matemática, é preciso utilizar tais habilidades.

Os jogos pedagógicos podem ser disponibilizados, na maioria dos casos, descritos em português, espanhol ou inglês e, assim, podem oferecer uma ferramenta de interação múltipla, permitindo que a criança tenha maior e mais frequente contato com as diferentes línguas através de outros jogadores. Este contato direto com o idioma auxilia na aprendizagem e/ou pode influenciar o jogador a buscar aprender outras línguas para conseguir desenvolver seu jogo. Domingos (2008) acredita que a aprendizagem só acontece através da repetição de conteúdos, onde o aluno precisa rever para relembrar, já que aprender exige familiarização com o conteúdo.

(...) o jogo torna-se uma ferramenta ideal para a aprendizagem, na medida em que estimula o interesse do aluno, ajudando-o a construir novas descobertas, enriquecendo sua personalidade e é uma estratégia pedagógica que permite ao professor se colocar na condição de condutor, incentivador e avaliador de aprendizagem.

Os jogos eletrônicos podem ser utilizados no ensino da Educação Infantil, por exemplo, auxiliando de duas maneiras: como uma ferramenta de prática de aprendizagem, na qual o aluno que já conhece um pouco do alfabeto pode utilizar o contexto e os métodos do jogo para praticar e desenvolver ainda mais o que já sabe a língua; e como um entretenimento que influencie de forma inconsciente o aluno a sentir o desejo de desenvolver práticas de leitura e letramento, para compreender o contexto e para desenvolver suas habilidades no jogo. Como cita Teixeira (1995),

O jogo é um fator didático altamente importante; mais do que um passatempo, ele é elemento indispensável para o processo ensino- aprendizagem. Educação pelo jogo deve, portanto, ser a preocupação básica de todos os professores que têm intenção de motivar seus alunos ao aprendizado.

Para Antunes (2008), o uso dos jogos permite ao aluno desenvolver várias habilidades especiais, como: retenção de informação, criatividade, planejar suas ações dentro do jogo, formular hipóteses para tomar decisões firmes e certeiras que validem ou invalidem estas hipóteses ao desenvolver do jogo. No ensino-aprendizagem, diante da Educação Infantil, o jogo pode ser utilizado no ambiente escolar como um meio de atingir grandes resultados no desenvolvimento do aluno, podendo ser explorado de forma prazerosa, servindo como um meio de partida para que o aluno possa se manter em frequente contato com as habilidades necessárias à alfabetização e ao raciocino lógico-matemático.

Devido ao frequente contato com as letras e sons através dos meios tecnológicos, muitas barreiras à alfabetização têm se dissipado, deixando de ser um obstáculo para a criança. O universo do multimeios, dos jogos e dos aplicativos pedagógicos desenvolvem autonomia, transformando os educandos da Educação Infantil em sujeitos de sua própria aprendizagem, ou seja, desenvolvendo, neles, a capacidade pessoal de 
selecionarem, buscarem e construírem um conjunto de práticas para aprimorar seus conhecimentos, consequentemente, sua aprendizagem.

Para Dickinson (1994) "a autonomia na aprendizagem é essencialmente uma questão de atitude em relação à aprendizagem", ou seja, a autonomia auxilia a criança a buscar seus objetivos de acordo com as suas necessidades, sempre redescobrindo recursos e meios para aprender. A partir disso, o processo de aprendizagem deixa de ser uma reprodução de informação e passa a fazer sentido na vida do aprendiz.

Almeida Filho (2002) afirma que a competência linguística vai ser aprendida para e na comunicação sem se restringir apenas ao domínio de suas formas e do seu funcionamento enquanto sistema. Para que a aprendizagem tenha sentido, é necessário que seja concebido em conjunto e em relação a outras coisas. Portanto, é preciso que o aprendiz esteja envolvido ou se envolva em situações reais de interação, de comunicação efetiva, interagindo com outros na intenção de trocar experiências que contribuam no desenvolvimento da aprendizagem. No ciberespaço, pode-se encontrar milhões de contribuições acessíveis de diferentes formas para desenvolver o ensino e aprendizagem na Educação Infantil por meio das tecnologias e dos multimeios, como: imagem, texto, vídeo, áudio, entre outros.

\section{CONCLUSÕES}

Qualquer meio que sirva como um condutor no auxílio das práticas de aprendizagem pode ser considerado como tecnologia. Os livros, como primeiros e principais condutores na aprendizagem foram nossos pioneiros nessa junção de páginas, escrita e conhecimento. Com o passar do tempo, foram sendo acrescentados cadernos, gizes, canetas, lápis, borrachas, mapas, telescópios, aparelhos multifuncionais, projetores, computadores e a internet. Atualmente o método de ensino tem se tornado cada vez mais prático em qualquer lugar do mundo graças ao auxílio tecnológico, tornando os meios de pesquisa e a informação algo mais rápido e prático de se alcançar.

$\mathrm{Na}$ realidade de hoje, isto tem se desenvolvido de forma completamente diferente. Vemos um aprendiz capaz de desenvolver sua aprendizagem com autonomia, auxiliado pelos meios eletrônicos e com a contribuição da internet. O professor agora é um condutor de informação e experiências que se envolve com seu aluno e suas experiências para auxiliá-lo por que caminhos deve percorrer.

Hoje, as crianças assumem a presença de tecnologias na sociedade como normal. Eles vivem com eles e adotá-los sem dificuldade para o seu uso diário. Neste sentido, os professores devem promover uma educação de acordo com o nosso tempo, fazendo novas propostas de ensino e introduzindo as ferramentas necessárias para esse fim.

Diante das atuais políticas, a maioria de crianças têm o primeiro contato com uma escola desde muito cedo e, ao contrário dos tempos precedentes, em que esta fase da instrução da primeira infância não foi dada a grande importância, é considerada atualmente relevante, uma vez que estabelece os fundamentos das aprendizagens futuras, adquirindo hábitos de comportamento e de convivência. Nessa fase, há grandes mudanças de crescimento intelectual, nas quais as crianças adquirem grande capacidade de aprendizado. 
Estas e outras características, permitem que se considere que a ação educativa realizada neste período será fundamental no seu subsequente processo evolutivo.

Esta ação educacional deve considerar o uso das tecnologias como recursos para a estimulação da criatividade, a experimentação e manipulação, o respeito ao ritmo de aprendizado dos alunos. Além disso os multimeios digitais direcionam ainda para o trabalho grupal, favorecendo a socialização; para despertar a curiosidade e o espírito de pesquisa.

Cada vez mais, as tecnologias integraram as práticas nas salas de aula de educação infantil, seja por meio de computadores, tablets, lousas digitais, aparelhagens de multimídias, entre outros. Há muitas ocasiões na educação infantil que os meios de aprendizagem digitais são usados no sentido de criar autonomia estudantil, incentivar o uso cooperativo e colaborativo entre os alunos e melhorar as capacidades motoras.

Os multimeios digitais e os aplicativos educacionais podem ajudar a desenvolver o conteúdo sistematicamente; facilitar a compreensão dos conceitos; estimular novos aprendizados; motivar a comunicação, tanto de pares como de professor-aluno. Contudo, para trazer este recurso em nossa sala de aula, o papel do professor é fundamentalmente, porque ele necessita se capacitar e ter um certo domínio das tecnologias, a fim de poder ensinar a sua utilização às crianças. Além disso, faz-se imprescindível integrar as ferramentas tecnológicas em sala de aula da Educação Infantil com um propósito educativo claro, centrado no trabalhando colaborativo.

\section{REFERÊNCIAS}

ALMEIDA FILHO, J. C. P.. Dimensões Comunicativas no Ensino de Línguas. 3 ed. Campinas: Pontes, 2002.

ANTUNES, C.. Inclusão: o nascer de uma nova pedagogia. São Paulo: Ciranda Cultural, 2008.

AYRES, S. R. B.. Projetos de aprendizagem articulados ao uso das TIC: abertura para o diálogo interdisciplinar na formação de professores. Dissertação (Mestrado) Universidade do Estado de Mato Grosso, Cáceres, 2012.

BERSCH, R.; SARTORETTO, M.. Educação, Tecnologia e Acessibilidade. São Paulo: 2015.

CONFORTO, D.; VIEIRA, M. C.. Smartphone na escola: Discussão Disciplinar para a Pedagógica. Latin American Journal of Computing, v.2, n.3, 2015.

COPE, B.; KALANTZIS, M.. Multiliteracies in Education. Pedagogies, v.4, n.3, p.164-195, 2013.

DICKINSON, L.. Learner autonomy: what, why and how?. In: LEFFA, V.. Autonomy in language learning. Porto Alegre: EDUFRGS, 1994.

DOMINGOS, J.. Jogos didáticos e o desenvolvimento do raciocínio geométrico. São Paulo: 2008.

GIL, A. C.. Como elaborar projetos de pesquisa. 8 ed. São Paulo: Atlas, 2017.
KRESS, G.. Literacy in the new media age. New York: Routledge, 2003.

MORAN, J. M.. Novas tecnologias e mediações pedagógicas. Campinas: Papirus, 2000.

PIROZI, G. P.. Tecnologia ou Metodologia? O grande desafio para o século XXI. Pitágoras, Nova Andradina, v.4, n.4, 2013.

PRENSKY, M.. Digital Game-Based Learning. Saint Paul: Paragon House, 2007.

RIBEIRO, L. O. M.. Modificações em jogos digitais e seu uso potencial como tecnologia educacional para o ensino de engenharia. Novas Tecnologias na Educação, Porto Alegre, v.4, n.1, 2006.

SERAFIM, M. L.; PIMENTEL, F. S. C.; SOUZA, A. P.. Aprendizagem colaborativa e interativa na web: experiências com o Google Docs no ensino de graduação. In: SIMPÓSIO HIPERTEXTO E TECNOLOGIAS NA EDUCAÇÃO, 2. Anais. Recife: UFPE, 2008.

SILVA, A. C.. Formação docente e práticas educativas na escola. Cuiabá: EDUFMT, 2015.

TEIXEIRA, C. E. J.. A ludicidade na escola. São Paulo: Loyola, 1995.

A CBPC - Companhia Brasileira de Produção Científica (CNPJ: 11.221.422/0001-03) detém os direitos materiais desta publicação. Os direitos referem-se à publicação do trabalho em qualquer parte do mundo, incluindo os direitos às renovações, expansões e disseminações da contribuição, bem como outros direitos subsidiários. Todos os trabalhos publicados eletronicamente poderão posteriormente ser publicados em coletâneas impressas sob coordenação da Sustenere Publishing, da Companhia Brasileira de Produção Científica e seus parceiros autorizados. Os (as) autores (as) preservam os direitos autorais, mas não têm permissão para a publicação da contribuição em outro meio, impresso ou digital, em português ou em tradução. 